\title{
Tricuspid atresia type 1B with left superior vena cava in a 4-month-old child: An unusual combination diagnosed by transthoracic echocardiography
}

\author{
Subrahmanya Murti Velamakanni ${ }^{1}$, Aman Patel $^{1}$, Gajanan Khadkikar $^{1}$, and Tejas Patel ${ }^{1}$ \\ ${ }^{1}$ Smt NHL Municipal Medical College
}

March 29, 2021

\begin{abstract}
Tricuspid atresia (TA) is a rare cyanotic congenital heart disease. A persistent left superior vena cava (LSVC) may be associated with TA. The presence of LSVC raises important considerations for eventual repair, in that it may lead to persistent arterial desaturation even after corrective surgery, if associated with an unroofed coronary sinus. Here, we present the case of a 4-month-old child who was diagnosed with TA type 1B, LSVC and a dilated coronary sinus by transthoracic echocardiography.
\end{abstract}

Article type: Images - Pediatric

Title: Tricuspid atresia type 1B with left superior vena cava in a 4-month-old child: An unusual combination diagnosed by transthoracic echocardiography

Authors

1. Subrahmanya Murti Velamakanni, MD, Resident physician, Department of Cardiology, Smt NHL Municipal Medical College, Ahmedabad, India

2. Aman Tejas Patel, MD, Resident physician, Department of Cardiology, Smt NHL Municipal Medical College, Ahmedabad, India

3. Gajanan Khadkikar, MD, Resident physician, Department of Cardiology, Smt NHL Municipal Medical College, Ahmedabad, India

4. Tejas Patel, DM, Professor and head, Department of Cardiology, Smt NHL Municipal Medical College, Ahmedabad, India

Corresponding author: Subrahmanya Murti Velamakanni, Room 12060, SVP Hospital, Ellisbridge, Ahmedabad, India. Email id: subrahmanyamurti@gmail.com

Keywords: tricuspid atresia, left superior vena cava, cyanotic congenital heart disease, coronary sinus

Abstract

Tricuspid atresia (TA) is a rare cyanotic congenital heart disease. A persistent left superior vena cava (LSVC) may be associated with TA. The presence of LSVC raises important considerations for eventual repair, in that it may lead to persistent arterial desaturation even after corrective surgery, if associated with an unroofed coronary sinus. Here, we present the case of a 4-month-old child who was diagnosed with TA type 1B, LSVC and a dilated coronary sinus by transthoracic echocardiography.

Article text

Tricuspid atresia (TA) is a rare cyanotic congenital heart disease with an estimated incidence of 79 per million live births. ${ }^{1}$ Tricuspid atresia has been classified according to the modified Edward-Burchells classification 
into three major types based on the relations of the great arteries and degree of pulmonary stenosis. ${ }^{2} \mathrm{~A}$ persistent left superior vena cava (LSVC) may be associated with TA and raises an important consideration for eventual repair, in that it may lead to persistent arterial desaturation even after corrective surgery if associated with an unroofed coronary sinus. ${ }^{3}$ Here, we present the case of a cyanosed 4-month-old child who presented with failure to thrive. On examination, a grade 4/6 pan-systolic murmur was heard in the left lower sternal border with no other obvious dysmorphic features. On transthoracic echocardiography, there was situs solitus and levocardia. A large ostium secondum atrial septal defect (ASD) was noted with predominant right to left shunting (figure 1). The tricuspid valve was atretic with no flow across the same. On examination in the parasternal long axis view, a dilated coronary sinus (CS) was noted (figure 2). A large sub aortic ventricular septal defect was seen with left to right shunting filling a hypoplastic right ventricle and the left ventricle was dilated (figure 3A). The pulmonary valve was morphologically normal, main pulmonary artery was dilated and branch pulmonary arteries were normal. A patent ductus arteriosus was present with a left to right shunt (figure 3B). On modified high parasternal views, LSVC was identified (figure 4A). A right ventricular outflow tract maximum gradient of about $50 \mathrm{mmHg}$ was seen suggesting moderate sub-pulmonary stenosis (figure 4B). Atrio-ventricular and ventriculo-arterial concordance was preserved. Pulmonary venous return was normal. As per the modified Edwards-Burchells classification, this was a type 1B TA. Most children with TA require the Glenn's or the Fontan's shunt for correction. An associated LSVC and unroofed CS with TA has been less reported and assumes importance for eventual corrective surgery. ${ }^{4}$ Therefore, in all cases of TA, an LSVC must be sought for, and confirmed using either contrast echocardiography or cardiac computed tomography (CT) as it may have important operative implications.

References

1. Hoffman JI, Kaplan S. The incidence of congenital heart disease. J Am Coll Cardiol. 2002 Jun 19;39(12):1890-900

2. Tandon R, Edwards JE. Tricuspid atresia. A re-evaluation and classification. J Thorac Cardiovasc Surg. 1974 Apr;67(4):530-42

3. Gupta MD, Girish MP, Ramakrishnan S. Persistent left superior vena cava draining into an unroofed coronary sinus in tricuspid atresia: an uncommon anomaly. Pediatr Cardiol. 2011 Apr;32(4):530-1

4. Burch M, Stark J, Sullivan I. Unexpected oxygen desaturation after cardiopulmonary bypass: rapid confirmation of unroofing of the coronary sinus by intraoperative epicardial echocardiography. Pediatr Cardiol. 1995 Jul-Aug;16(4):197-200

Legends to figures

Figure 1: A: Showing a subcostal view with color doppler demonstrating an ostium secondum atrial septal defect with predominant right to left shunt, B: Subcostal bicaval view showing the atrial septal defect. LA - left atrium, RA - Right atrium, OS-ASD - Ostium Secondum atrial septal defect

Figure 2: A: Parasternal long axis view showing a dilated coronary sinus, B: Foreshortened apical view showing a dilated coronary sinus. LA - left atrium, LV- left ventricle, RA - Right atrium, RV - Right ventricle, Ao - Aorta, CS - Coronary sinus

Figure 3: A: Showing an apical four chamber view, B: Color doppler of the parasternal short axis view showing a patent ductus arteriosus with left to right shunt. LA - left atrium, LV- left ventricle, RA Right atrium, RV - Right ventricle, RVOT - RV outflow tract Ao - Aorta, TV - Tricuspid Valve, VSD - Ventricular septal defect, PDA - Patent ductus arteriosus, MPA - Main pulmonary artery, LPA - Left pulmonary artery

Figure 4: A: Color doppler of a high parasternal view showing a left superior vena cava, B: Showing a maximum gradient of $50 \mathrm{mmHg}$ on continuous wave doppler of the right ventricular outflow tract. LV - Left ventricle, SVC - Superior Vena Cava

Supplementary material: Movie clip for figures 1,2,3,4 

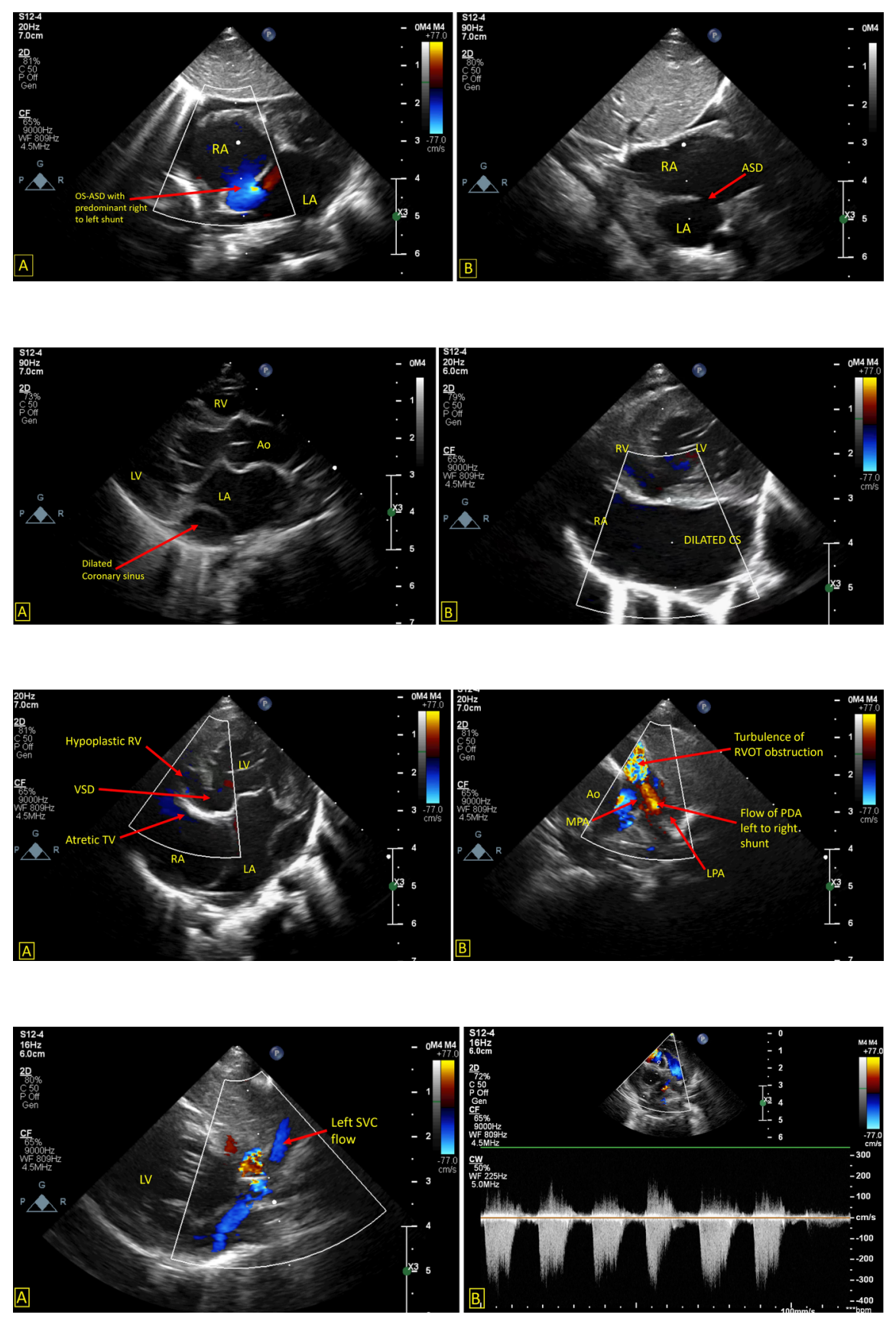